\title{
Nitrification of Reactively Magnetron Sputter Deposited Ti-Cu Nano-Composite Thin Films
}

\author{
Ali Rahmati \\ Department of Physics, Faculty of Science, Valieasr University of Rafsanjan, Rafsanjan, Iran. \\ Email: a.rahmati@vru.ac.ir, alirahmati1980@gmail.com \\ Received September $27^{\text {th }}, 2012$; revised November $28^{\text {th }}, 2012$; accepted December $17^{\text {th }}, 2012$
}

\begin{abstract}
A metalloid $\mathrm{Ti}_{13} \mathrm{Cu}_{87}$ target was sputtered by reactive DC magnetron sputtering at various substrate temperatures in an Ar- $\mathrm{N}_{2}$ mixture ambient. The sputtered species were condensed on $\mathrm{Si}(111)$, glass slide and Potsssium bromide (KBr) substrates. The as-deposited films were characterized by X-ray diffraction (XRD), Fourier transform infrared (FTIR) spectroscopy, Scanning electron microscope (SEM), energy dispersive X-ray spectroscopy (EDX), optical spectrophotometry and four point probe technique. The as-deposited films present composite structure of nano-crystallite cubic anti- $\mathrm{ReO}_{3}$ structure of Ti inserted $\mathrm{Cu}_{3} \mathrm{~N}\left(\mathrm{Ti}_{\mathrm{C}} \mathrm{Cu}_{3} \mathrm{~N}\right)$ and nano-crystallite face centre cubic (fcc) structure of $\mathrm{Cu}$. The titanium atoms and sequential nitrogen excess form a solid solution within the $\mathrm{Cu}_{3} \mathrm{~N}$ crystal structure and accommodate in crystal lattice and vacant interstitial site, respectively. Depending on substrate temperature, unreacted N atoms interdiffuse between crystallites and their (and grain) boundaries. The films have agglomerated structure with atomic $\mathrm{Ti}: \mathrm{Cu}$ ratio less than that of the original targets. A theoretical model has been developed, based on sputtering yield, to predict the atomic $\mathrm{Ti}: \mathrm{Cu}$ ratio for the as-deposited films. Film thickness, refractive index and extinction coefficient are extracted from the measured transmittance spectra. The films' resistivity is strongly depending on its microstructural features and substrate temperature.
\end{abstract}

Keywords: Nano-Composite; Reactive Magnetron Sputtering; Ti Inserted $\mathrm{Cu}_{3} \mathrm{~N}$; Interstitial N Excess

\section{Introduction}

Various researches demonstrated the possibility of obtaining a large variety of non-equilibrium microstructure and phase compositions in thin films produced by DC magnetron sputtering. Particularly, several studies were focused on the production of metal alloys made of partly miscible or immiscible elements, deposited in chemically inert (Ar) or in reactive (e.g. Ar- $\mathrm{N}_{2}$ ) atmosphere. The potential interest in magnetron sputter process rely on the possibility of producing thin films with new properties, markedly different from those of corresponding equilibrium bulk phases when one considers a nano-composite that can be formed, e.g. by combining nano-crystalline phases or by embedding nano-crystalline domains in an amorphous matrix. It is now demonstrated that co-deposition of elements (from different targets or from a mixed target) whose phase diagram presents a wide miscibility gap is a prerequisite for forming non-equilibrium nanocrystalline or amorphous phases. This tendency to form non-crystalline phase is further increased by sputter deposition in a reactive atmosphere [1-9].

Copper nitride has been attracted much attentions due to its low decomposition temperature and sequential ap- plications as write-once optical recording media [10-12], as micrometric conductive lines [13], as an insulating barrier in magnetic tunnel junctions [14]. Although, copper nitride has been widely studied, but little information is available in the literature concerning $\mathrm{Cu}_{3} \mathrm{~N}$ based composite thin films. In this study, a titanium copper bicomponent target was reactively sputtered at $\mathrm{Ar}-\mathrm{N}_{2}$ ambient at various substrate temperatures. The aims of this communication are to investigate micro-structural, morphological, chemical, some electrical and optical properties of reactive DC magnetron sputter deposited and nitrided Ti-Cu films.

\section{Experimental Methods}

A sintered $\mathrm{Ti}-\mathrm{Cu}$ target (13 at.\%Ti, $76 \mathrm{~mm}$ in diameter and $4.5 \mathrm{~mm}$ thickness) was reactively sputtered at $\mathrm{Ar}-\mathrm{N}_{2}$ gas mixture, and the sputtered species were deposited on ultrasonically pre-cleaned $\mathrm{Si}(111)$, glass slide and $\mathrm{KBr}$ substrates. The deposition conditions were listed in Table 1.

The films structure was studied by X-ray diffraction (XRD) in $\theta / 2 \theta$ scan mode with $\mathrm{CuK} \alpha$ radiation $(1.5418 \AA)$. The crystallites size was estimated from the 
full width at half maximum (FWHM) of strongest XRD peak using Scherrer formula. The chemical bonding was characterized by Fourier transform infrared (FTIR) spectroscopy (FTIR spectrometer Bruker Tensor 27). Films morphology and their chemical composition were determined using scanning electron microscope and energy dispersive X-ray spectrometer (SEM/EDX, Philips XL 30). Also, an estimation of the atomic ratio was made in according to sputtering yield. Optical studies were performed by measuring transmittance in the wavelength region $360-1100 \mathrm{~nm}$ using spectrophotometer (Shimadzu, UV-1700 Pharma Spec) at room temperature. These measurements allowed obtaining refractive index, extincttion coefficient and meaning film thickness. The electrical resistivity of the films at room temperature was deduced from measurement using four point probe method.

\section{Results and Discussion}

\subsection{Structural Properties and Chemical Bonding}

Figure 1 shows the effect of substrate temperature on Xray diffraction (XRD) pattern of nitrided Ti-Cu thin films deposited on $\mathrm{Si}$ (111) substrate. The films are amorphous at lower substrate temperature (i.e. $45^{\circ} \mathrm{C}$ ), but at higher substrate temperature $\left(70^{\circ} \mathrm{C}, 110^{\circ} \mathrm{C}, 150^{\circ} \mathrm{C}\right.$ and $\left.180^{\circ} \mathrm{C}\right)$, they are composed of nano-crystallite cubic anti $\mathrm{ReO}_{3}$ structure of Ti inserted $\mathrm{Cu}_{3} \mathrm{~N}\left(\mathrm{Ti}_{\mathrm{i}} \mathrm{Cu}_{3} \mathrm{~N}\right)$ and nano-crystallite fcc structure of $\mathrm{Cu}$.

Copper nitride has a cubic anti- $\mathrm{ReO}_{3}$ type structure and exhibits a vacant site at the centre of the cell [15]. Ti atoms cannot exclusively be positioned at the centre of a stoichiometric $\mathrm{Cu}_{3} \mathrm{~N}$ cell. The lattice constant has been estimated from the position of the (100) diffraction peak of $\mathrm{Cu}_{3} \mathrm{~N}$ structure. Table 2 indicates the lattice constant of $\mathrm{Ti}$ inserted $\mathrm{Cu}_{3} \mathrm{~N}\left(\mathrm{Ti}: \mathrm{Cu}_{3} \mathrm{~N}\right)$ at various substrate temperatures. Indeed, the value of the lattice constant of $\mathrm{Ti}: \mathrm{Cu}_{3} \mathrm{~N}$ crystallites (except for samples prepared at sub strate temperature of $150^{\circ} \mathrm{C}$ ) is still lower than the calculated value of $\mathrm{Cu}_{3} \mathrm{MN}(\mathrm{M}=\mathrm{Cu}, \mathrm{Zn}, \mathrm{Pd}, \mathrm{Ag})$ [16]. Since titanium atom exhibits a higher radius than $\mathrm{M}=\mathrm{Cu}$, $\mathrm{Zn}, \mathrm{Pd}$ and $\mathrm{Ag}$ ones, substitution of the vacant site by titanium atoms in a $\mathrm{Cu}_{3} \mathrm{~N}$ cell centered by titanium may not be further considered. Here, the formation of copper vacancies in $\mathrm{Cu}_{3} \mathrm{~N}$ cell substituted by Ti atoms was considered to explain the measured lattice constant. Lattice constant for sample prepared at substrate temperature of $150^{\circ} \mathrm{C}$ has lower value than stoichiometric Ti-free $\mathrm{Cu}_{3} \mathrm{~N}$ (i.e. $0.3815 \mathrm{~nm}$ [17]). In most works, the stoichiometry of $\mathrm{Cu}_{3} \mathrm{~N}$ thin films has been deduced from XRD data (having a change in the lattice parameter) [17-23].

The evolution of the film lattice constant is due to the variation in nitrogen stoichiometry [24-26]. However, there is no information about the position of excess nitrogen in the $\mathrm{Cu}_{3} \mathrm{~N}$ unit cell [24]. Due to sensitivity of
Table 1. The deposition conditions.

\begin{tabular}{cc}
\hline Sputtering power & $200 \mathrm{~W}$ \\
Base pressure & $2 \times 10^{-4} \mathrm{~Pa}$ \\
Substrate temperatures & $45^{\circ} \mathrm{C}-180^{\circ} \mathrm{C}$ \\
Total gas pressure & $0.6 \mathrm{~Pa}$ \\
Target-substrate distance & $19 \mathrm{~cm}$ \\
Deposition time & $50 \mathrm{~min}$ \\
Ar flow rate & $25 \mathrm{sccm}$ \\
$\mathrm{N}_{2}$ flow rate & $15 \mathrm{sccm}$ \\
\hline
\end{tabular}

Table 2. Deposition conditions, deposition rate, lattice constant and mean crystallite size of $\mathrm{Ti}: \mathrm{Cu}_{3} \mathrm{~N}$, atomic $\mathrm{Ti}: \mathrm{Cu}$ ratio and resistivity of the nitrided $\mathrm{Ti}-\mathrm{Cu}$ films at different substrate temperature.

\begin{tabular}{cccccc}
\hline $\begin{array}{c}\text { Substrate } \\
\text { temperature }\left({ }^{\circ} \mathbf{C}\right)\end{array}$ & $\begin{array}{c}\mathbf{R} \\
(\mathbf{n m} / \mathbf{m i n})\end{array}$ & $\mathbf{a}(\mathbf{n m})$ & $\mathbf{D}(\mathbf{n m})$ & $\mathbf{T i}: \mathbf{C u}$ & $\begin{array}{c}\text { Resistivity } \\
(\boldsymbol{\mu} \boldsymbol{\Omega} \mathbf{c m})\end{array}$ \\
\hline 45 & 12.83 & - & - & 0.049 & 3100 \\
70 & 13.44 & 0.3841 & 21 & 0.057 & 1875 \\
110 & 12.21 & 0.3840 & 23 & 0.088 & 1145 \\
150 & 12.13 & 0.3789 & 12 & 0.065 & 1523 \\
180 & 14.57 & 0.3821 & 21 & 0.062 & 984 \\
\hline
\end{tabular}

chemical composition to characterization method, lattice constant of $\mathrm{Cu}_{3} \mathrm{~N}$ revealed good qualitative criterion for composition determination. The samples prepared at substrate temperature of $70^{\circ} \mathrm{C}, 110^{\circ} \mathrm{C}, 180^{\circ} \mathrm{C}$ are $\mathrm{N}$ rich or over-stoichiometric, but the sample prepared at substrate temperature of $150^{\circ} \mathrm{C}$ is $\mathrm{N}$ poor or substoichiometric. Addition of titanium to $\mathrm{Cu}_{3} \mathrm{~N}$ films does not change the cubic anti $\mathrm{ReO}_{3}$ structure of $\mathrm{Cu}_{3} \mathrm{~N}$ (Figure 1). Within the deposition conditions tested in this study (except the samples prepared at substrate temperature of $150^{\circ} \mathrm{C}$ ), the both of $\mathrm{Ti}: \mathrm{Cu}_{3} \mathrm{~N}$ and $\mathrm{Cu}$ phases are detected by XRD. No metallic titanium or titanium nitride diffraction lines are exhibited. Figure 2 depicts FTIR spectra of nitrided Ti$\mathrm{Cu}$ films deposited on $\mathrm{KBr}$ substrate at various substrate temperature, the infrared absorption of which has been deduced. Typical absorption bands occurred around 667 and $1037 \mathrm{~cm}^{-1}$ are attributed to $\mathrm{Cu}-\mathrm{N}$ and Ti-N stretch vibrations, respectively $[13,27,28]$. The Ti-N bond formation shows, titanium addition accommodates $\mathrm{N}$ excess in vacant interstitial lattice site of $\mathrm{Ti}$ free $\mathrm{Cu}_{3} \mathrm{~N}$ structure.

Using the broadening of the peaks, it is possible to determine mean crystallite size, from Scherrer formula (Warren) [29]. The mean crystallite size $(D)$ of any phase may be determined by the equation:

$$
D=\frac{0.94 \lambda}{(\beta-b) \operatorname{Cos} \theta_{B}}
$$


where, $\beta$ is the FWHM of the diffraction peak, $\lambda$ is the wavelength of the incident $\mathrm{CuK} \alpha \mathrm{X}$-ray and $\theta_{B}$ is Bragg diffraction angle. $\mathrm{b}$ is standard instrumental broadening $\left(0.08^{\circ}\right)$. The mean crystallite size of $\mathrm{Ti}_{\mathrm{C}} \mathrm{Cu}_{3} \mathrm{~N}$ is calculated by using strongest peak namely (100) peak (Table 2).

The presence of $\mathrm{N}$ neutrals reflected [30] from the single $\mathrm{TiCu}$ bi-component surface and impinging on the growing film with sufficient energy (due to large throw distance) can produce atomic scale heating in addition to substrate temperature which decompose the metastable $\mathrm{Ti}: \mathrm{Cu}_{3} \mathrm{~N}$ nano-crystallites to copper and escaped nitrogen [31]. This phenomenon becomes more significant at substrate temperature of $150^{\circ} \mathrm{C}$ ), because unbound $\mathrm{N}$ atoms out-diffuse from Ti: $\mathrm{Cu}_{3} \mathrm{~N}$ crystallite into intercrystallite boundaries. The mean crystallite size of $\mathrm{Ti}: \mathrm{Cu}_{3} \mathrm{~N}$ for the samples prepared at substrate temperature of $150^{\circ} \mathrm{C}$ has minimal value. It is due to $\mathrm{N}$ precipitation around the crystallites and suppression of their growth. As substrate temperature increases from $150^{\circ} \mathrm{C}$ to $180^{\circ} \mathrm{C}$, extra $\mathrm{N}$ concentration at inter-crystallite boundaries produces driving force to transport $\mathrm{N}$ into $\mathrm{Ti}: \mathrm{Cu}_{3} \mathrm{~N}$ crystallite. As it is seen, the lattice constant and mean crystallite size of Ti: $\mathrm{Cu}_{3} \mathrm{~N}$ increases up to substrate temperature of $180^{\circ} \mathrm{C}$

\subsection{Surface Morphology and Chemical Composition}

Surface morphology of the nitrided $\mathrm{Ti}-\mathrm{Cu}$ thin films

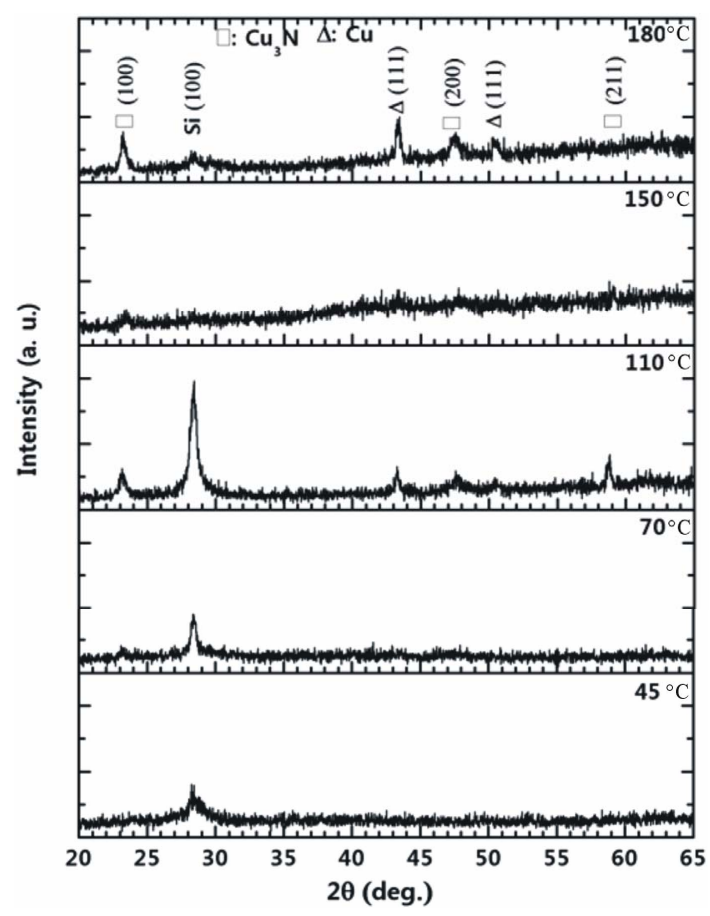

Figure 1. XRD pattern of nitrided Ti-Cu films at various substrate temperatures.

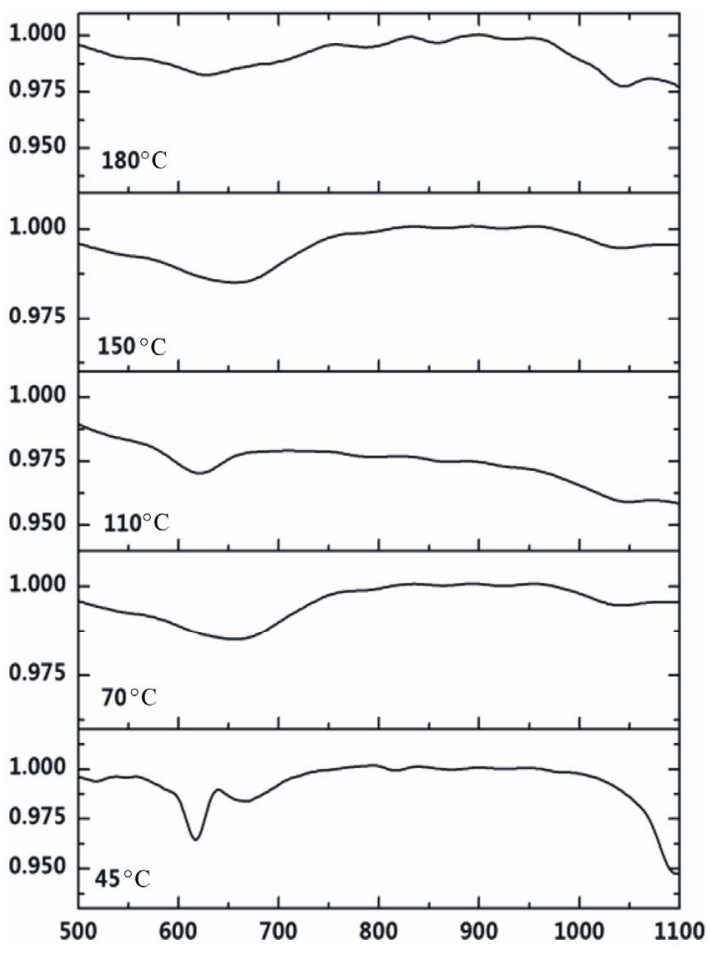

Figure 2. The FTIR spectra of nitrided Ti-Cu films deposited at various substrate temperatures.

deposited at substrate temperature are shown in Figure 3. The films have granular structure with clear grain structure and sharp grain boundaries. The extra nitrogen atoms that are not located at vacant interstitial site of $\mathrm{Ti}: \mathrm{Cu}_{3} \mathrm{~N}$ crystal structure or not trapped at crystallite boundaries diffuse into grain boundaries. This mechanism suppresses the agglomeration of grain because of $\mathrm{N}$ precipitation around them. Surface roughness of the films increases with increase in substrate temperature [32-35].

In order to estimate the atomic Ti:Cu ratio in films, we make the following assumptions:

- difference in throw distance of any sputtered component in target-substrate spacing;

- difference in nitriding kinetics on target surface of any component;

- difference in sticking coefficient of any sputtered component on substrate;

- re-sputtering contribution in altering the chemical composition due to the reflected $\mathrm{N}$ neutral and the sputtered $\mathrm{Ti}$ and $\mathrm{Cu}$ atoms collide with the growing film are excluded. The atomic $\mathrm{Ti}: \mathrm{Cu}$ ratio can roughly be calculated by [25].

$$
\mathrm{Ti}: \mathrm{Cu}=\frac{c_{b}^{T i}}{1-c_{b}^{T i}} \cdot \frac{P_{N_{2}}^{r} Y_{T i}^{N_{2}}+P_{A r}^{r} Y_{T i}^{A r}}{P_{N_{2}}^{r} Y_{C u}^{N_{2}}+P_{A r}^{r} Y_{T i}^{A r}}
$$

where $c_{b}^{T i}$ is $T i$ concentration in target surface. $P_{j}^{r}$ is relative partial pressure of jth gas, $j=N_{2}$ and $A r . Y_{i}^{j}$ is sputtering yield of ith atom due to jth species, $I=\mathrm{Ti}, \mathrm{Cu}$. 


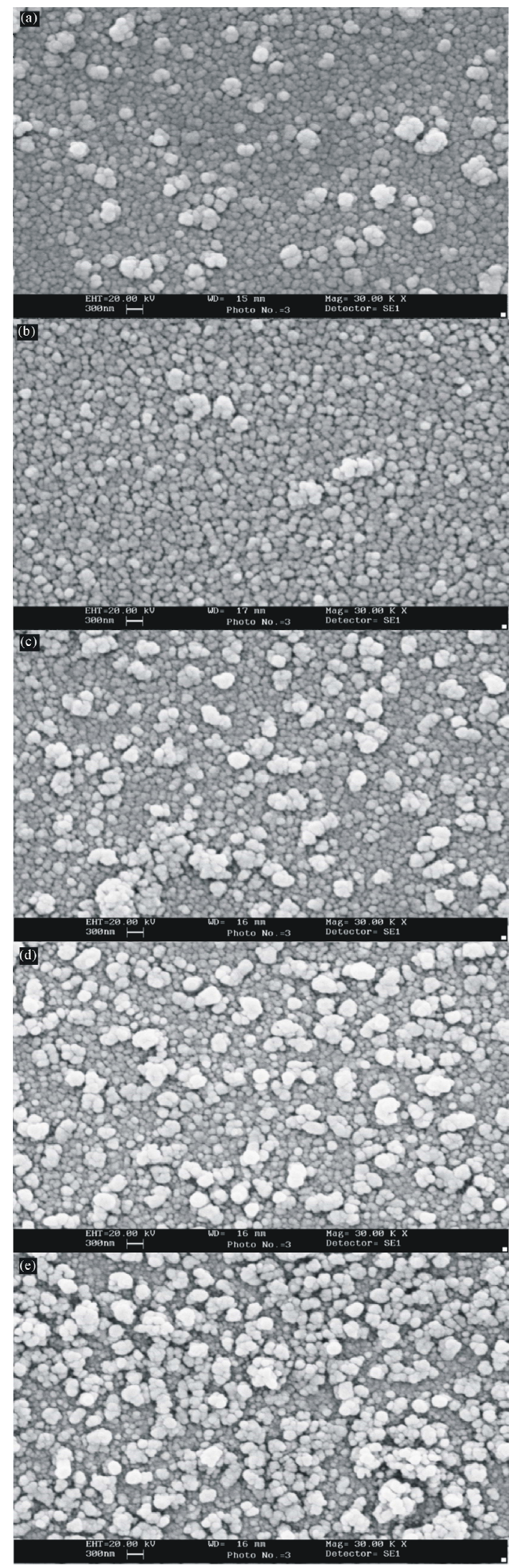

Figure 3. SEM images of the nitrided Ti-Cu films prepared at (a) $45^{\circ} \mathrm{C}$; (b) $70^{\circ} \mathrm{C}$; (c) $110^{\circ} \mathrm{C}$; (d) $150^{\circ} \mathrm{C}$; (e) $180^{\circ} \mathrm{C}$.
We assume $N_{2}^{+}$ion bombardment acts as same as two separate $N^{+}$ions with half energy. Sputtering yield is depending on energy and angular such as

$$
Y(E, \theta)=Y(E) \cdot S(\theta)
$$

where $E$ is the energy of incident ions and is approximately equal to $0.75 \mathrm{eVd}$ [36]. $\theta$ is the ejection angle of sputtered atoms with respect to the surface normal. Energy dependent part is given by Eckstein et al. [37] as

$$
Y(E)=q s_{n}^{K r C}(\varepsilon) \frac{\left(\frac{E}{E_{t h}}-1\right)^{\mu}}{\lambda+\left(\frac{E}{E_{t h}}-1\right)^{\mu}}
$$

$q, E_{t h}, \mu$ and $\lambda$, which are material dependent parameters, listed in Table 3 for pairs of incident ion and target atom. $E_{t h}$ and $S_{n}^{K r C}(\varepsilon)$ are threshold energy for sputtering and nuclear stopping power, respectively.

Angular distribution of sputtered atom is proposed by Yamamura et al. [38] as heart shape

$$
S(\theta)=\cos \theta\left(1+\beta \cos ^{2} \theta\right)
$$

where $\beta$ is a fitting parameter. The fitting parameter depends on the mass and binding energy of the target material, mass and ion energy. It may be expressed as

$$
\begin{aligned}
& \beta=B \operatorname{Ln} Q-B_{c} \\
& Q=\frac{M_{t} E}{M_{g} E_{s b}}
\end{aligned}
$$

where $M_{t}$ is the mass of the sputtered atom, $E_{s b}$ is binding energy of the sputtered material (Table 3). The values of $B$ and $B_{c}$ were respectively approximated as 0.488 and 2.44. The near normal ejection $(\theta \approx 0)$ of $\mathrm{Ti}: \mathrm{Cu}$ atomic ratio is nearly calculated 0.073 through Equation (2) for different substrate temperature. There is a good agreement between the calculated and experimental values for Ti: $\mathrm{Cu}$ atomic ratio (Table 2).

The atomic Ti: $\mathrm{Cu}$ ratio is shown in Table 2 . As the substrate temperature increases, the atomic $\mathrm{Ti}: \mathrm{Cu}$ ratio of the deposited films on Si (111) increases until 0.088 at $110^{\circ} \mathrm{C}$ and then decreases. It seems by increasing substrate temperature to $110^{\circ} \mathrm{C}$, surface adsorption of Ti atoms increases. Afterward, re-evaporation of $\mathrm{Ti}$ atoms occurs (due to lower mass in comparison to $\mathrm{Cu}$ ) from liquid phase in gas-liquid-solid growth mechanism of films that developed by Shaginyan et al. [39]. The Ti:Cu ratios are generally lower than atomic $\mathrm{Ti}: \mathrm{Cu}$ ratio of original $\mathrm{Ti}_{13} \mathrm{Cu}_{78}$ target, namely 0.15 . It was known that the near normal sputtering yield ratio of $\mathrm{Ti}$ to $\mathrm{Cu}$ is calculated 0.487 through Equation (4). Also, when $\mathrm{Ti}$ is sputtered in an Ar- $\mathrm{N}_{2}$ mixture atmosphere, the sputtering yield is decreased because a part of Ti on the target surface is nitrided [40]. This effect is weaker for the $\mathrm{Cu}$ because 
Table 3. Materials dependent parameters presented by Eckstein et al. [37] for $\mathrm{Ti}$ and $\mathrm{Cu}$ target atoms bombarded by $\mathbf{N}$ and Ar ions.

\begin{tabular}{ccccccc}
\hline $\begin{array}{c}\text { Incident } \\
\text { ion or } \\
\text { atom }\end{array}$ & $\begin{array}{c}\text { Target } \\
\text { atom }\end{array}$ & $\lambda$ & $\boldsymbol{q}$ & $\mu$ & $\boldsymbol{E}_{\text {th }}(\mathbf{e V})$ & $\boldsymbol{E}_{\boldsymbol{s b}}(\mathbf{e V})$ \\
\hline $\mathrm{N}^{+}$ & $\mathrm{Ti}$ & 0.2321 & 1.8168 & 2.0297 & 16.5403 & 4.89 \\
$\mathrm{~N}^{+}$ & $\mathrm{Cu}$ & 0.1595 & 3.4102 & 2.1567 & 15.6557 & 3.52 \\
$\mathrm{Ar}^{+}$ & $\mathrm{Ti}$ & 0.3152 & 4.8957 & 1.8291 & 25.019 & 4.89 \\
$\mathrm{Ar}^{+}$ & $\mathrm{Cu}$ & 1.9417 & 14.8712 & 2.3907 & 12.9166 & 3.52 \\
\hline
\end{tabular}

it is more difficult to nitride $\mathrm{Cu}$ than $\mathrm{Ti}$ due to weaker $\mathrm{Cu}-\mathrm{N}$ bonding. After being sputtered for some time the $\mathrm{Ti}: \mathrm{Cu}$ ratio on the target surface will reach an equilibrium so that the ratio of the sputtered yield of the two materials are less than their ratio in the bulk target. Thus, it is likely that the difference between the composition in the target and film is caused by their different throw distance, nitriding kinetics, angular distribution of any sputtered component and different absorption rates on the film surface.

\subsection{Optical Properties}

There is an easy method for determination of optical constants, which depends on single transmittance measurement. The refractive index $n$ and the extinction coefficient $k$ as well as the thickness $d$ of polycrystalline nitrided $\mathrm{Ti}-\mathrm{Cu}$ thin films on thick quartz substrate were studied. They were determined from transmittance data only using PUMA approach and code described by Birgin et al. [41] used in our previous work [25,26,31]. Poelman et al. [42] have reviewed and tested PUMA approach and shown it to produce excellent estimate of optical constants of thin films.

The experimental transmittance data are compared with theoretical values, in PUMA code. The difference between the two values is minimized until a best solution is achieved for the refractive index $n$, the extinction coefficient $k$ and the film thickness $d$. Deposition rate $(R)$ has been calculated from the average film thickness at given deposition time (Table 2). The deposition rate is weakly depending on substrate temperature. Figures $\mathbf{4}$ and $\mathbf{5}$ show dispersion of the calculated refractive index $n$ and extinction coefficient $k$ as functions of wavelength. The absorption coefficient of Ti-Cu-N films is related to extinction coefficient through $\alpha=4 \pi k / \lambda$ (Figure 6).

The Ti: $\mathrm{Cu}_{3} \mathrm{~N}$ lattice constant (Table 1) and the fundamental band-gap edge (from Figure 6) have the same trend vs. substrate temperature. These behaviors simultaneously illustrate the effects of $\mathrm{N}$ content and $\mathrm{Ti}$ addition in changing the lattice constant and absorption process.

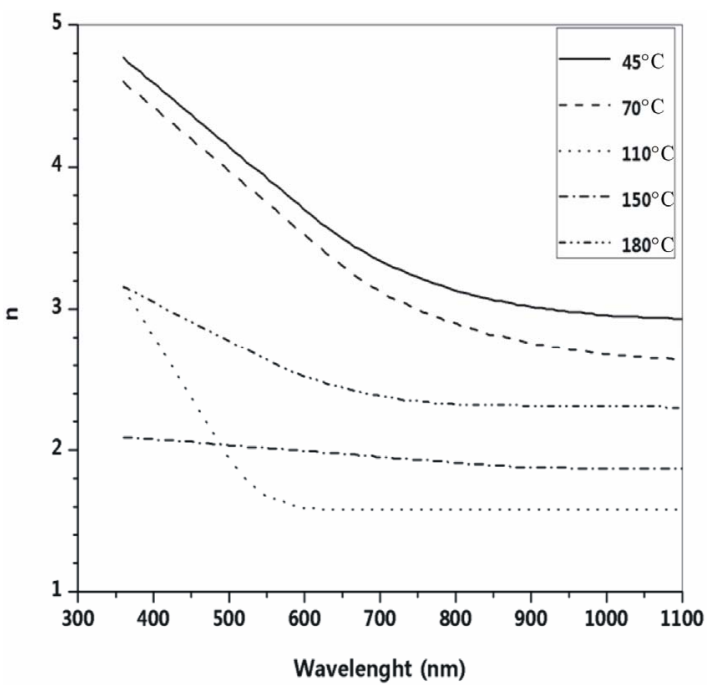

Figure 4. Dispersion of refractive index at various substrate temperatures.

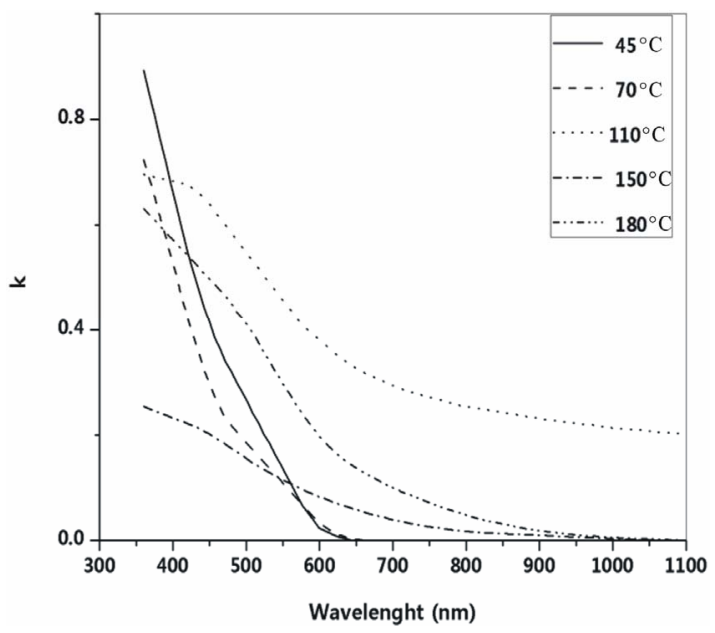

Figure 5. Dispersion of extinction coefficient at various substrate temperatures.

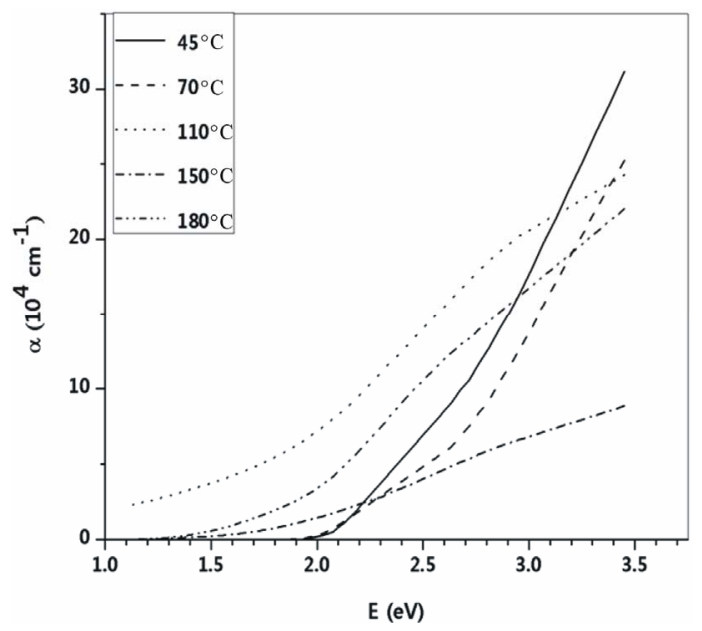

Figure 6. Variations of absorption coefficient with photon energy at various substrate temperatures. 


\subsection{Films Resistivity}

There have been reports that the resistivity of $\mathrm{Cu}_{3} \mathrm{~N}$ and $\mathrm{Cu}$ are $20 \mu \Omega \mathrm{cm}-2 \times 10^{3} \Omega \mathrm{cm}$ and $1.75-2 \mu \Omega \mathrm{cm}$, respectively [32]. The resistivity of nitrided $\mathrm{Ti}-\mathrm{Cu}$ films on glass slide at room temperature is presented in Table 2. The electrical conduction of films grown as the phase mixture (composite) of $\mathrm{Ti}: \mathrm{Cu}_{3} \mathrm{~N}$ nano-crystallite and $\mathrm{Cu}$ nanoparticle might follow the effective medium theory. Three simultaneous conduction mechanisms Ti: $\mathrm{Cu}_{3} \mathrm{~N}$ semiconducting conduction, $\mathrm{Cu}$ metallic conduction and tunneling through crystallite boundary play important roles in carrier transport [31]. The nanocomposite resistivity is correlated to scattering dislocation inside crystallite (intra-crystallite boundary effect), scattering from potential barrier due to intercrystallites boundary effect and scattering through nanocrystallite boundary (size effect) [31].

\section{Conclusion}

Nitrided Ti-Cu thin films were grown on Si (111), glass slide and $\mathrm{KBr}$ substrates by reactive DC magnetron sputtering of a sintered Ti-Cu bi-component target. The asdeposited films on $\mathrm{Si}$ (111) substrate have composite structure of $\mathrm{Ti}_{\mathrm{Cu}} \mathrm{Cu}_{3} \mathrm{~N}$ nano-crystallite and metallic $\mathrm{Cu}$ nano-particle. The titanium atoms are positioned in the $\mathrm{Cu}_{3} \mathrm{~N}$ crystal lattice and not segregated in other phases. The Ti addition causes to nitrogen excess; located at vacant interstitial site of $\mathrm{Ti}: \mathrm{Cu}_{3} \mathrm{~N}$ crystal structure, trapped at nano-crystallite and grain boundaries. The films have granular structure with clear grain boundaries. The atomic Ti:Cu ratio of films is less than that of the original target due to various differential sputtering yields, different throw distance and various sticking coefficient of any component. Refractive index, absorption coefficient and resistivity of the films are strongly dependent on substrate temperature and microstructural properties.

\section{Acknowledgements}

The corresponding author would like to acknowledge financial support of Iranian nanotechnology initiative. Also, he thanks Mohammad Safi Shalmazari from faculty of chemistry, university of Tabriz, for invaluable help. Also, he appreciates Department of Solid State and Electronics, Faculty of Physics, University of Tabriz, Tabriz, Iran.

\section{REFERENCES}

[1] J. Musil, "Magnetron Sputtering of Alloy and AlloyBased Films," Thin Solid Films, Vol. 343-344, 1999, pp. 47-50. doi:10.1016/S0040-6090(98)01567-3

[2] Y. F. Ding and C. Alexander Jr., "Effects of Ti on N Distribution and Diffusion in FeTiN Thin Films," IEEE
Transactions on Magnetics, Vol. 42, No. 1, 2006, pp. 511. doi:10.1109/TMAG.2005.860129

[3] J. F. Pierson, E. Tomasella and Ph. Bauer, "Reactively Sputtered Ti-B-N Nanocomposite Films: Correlation between Structure and Optical Properties," Thin Solid Films, Vol. 408, No. 1-2, 2002, pp. 26-32.

doi:10.1016/S0040-6090(02)00071-8

[4] P. Zeman, R. Cerstvy and P. H. Mayerhofer, "Structure and Properties of Hard and Superhard Zr-Cu-N Nanocomposite Coatings," Materials Science and Engineering: A, Vol. 239, No. 1-2, 2000, pp. 189-197. doi:10.1016/S0921-5093(00)00917-5

[5] J. Musil and H. Polakova, "Hard Nanocomposite Zr-Y-N Coatings, Correlation between Hardness and Structure," Surface and Coatings Technology, Vol. 127, No. 1, 2000, pp. 99-106. doi:10.1016/S0257-8972(00)00560-0

[6] N. N. Iosad, N. M. Van der Pers and S. Grachev, "Texture Formation in Sputter-Deposited $\left(\mathrm{Nb}_{0.7}, \mathrm{Ti}_{0.3}\right) \mathrm{N}$ Thin Films," Journal of Applied Physics, Vol. 92, No. 9, 2002, p. 4999. doi:10.1063/1.1510589

[7] H. Maezawa, T. Sato and T. Noguchi, "Process Simulation of Reactive DC Magnetron Sputtering for Thin Film Deposition of Niobium-Titanium Nitride," IEEE Transactions on Applied Superconductivity, Vol. 15, No. 2, 2005, pp. 3520-3523. doi:10.1109/TASC.2005.849027

[8] P. Scardi, Y. H. Dong and C. Tosi, "Co, Ni-Base Alloy Thin Films Deposited by Reactive Radio Frequency Magnetron Sputtering," Journal of Vacuum Science \& Technology A, Vol. 19, No. 5, 2001, p. 2394. doi:10.1116/1.1385907

[9] Z. L. Liu, X. G. Li and A. Y. Zuo, "Effect of $\mathrm{N}_{2}$-Gas Partial Pressure on the Structure and Properties of Copper Nitride Films by DC Reactive Magnetron Sputtering," Plasma Science and Technology, Vol. 9, No. 2, 2007, p. 147. doi:10.1088/1009-0630/9/2/06

[10] M. Asano, K. Umeda and A. Tasaki, " $\mathrm{Cu}_{3} \mathrm{~N}$ Thin Film for a New Light Recording Media," Japanese Journal of Applied Physics, Vol. 29, 1990, pp. 1985-1986. doi:10.1143/JJAP.29.1985

[11] T. Maruyama and T. Morishita, "Copper Nitride and Tin Nitride Thin Films for Write-Once Optical Recording Media," Applied Physics Letters, Vol. 69, 1996, p. 890. doi:10.1063/1.117978

[12] R. Cremer, M. Witthaut and D. Neuschutz, "Deposition and Characterization of Metastable $\mathrm{Cu}_{3} \mathrm{~N}$ Layers for Applications in Optical Data Storage," Microchimica Acta, Vol. 133, No. 1-4, 2000, pp. 299-302. doi:10.1007/s006040070109

[13] L. Maya, "Deposition of Crystalline Binary Nitride Films of Tin, Copper, and Nickel by Reactive Sputtering," Journal of Vacuum Science \& Technology A, Vol. 11, No. 3, 1993, p. 604. doi:10.1116/1.578778

[14] D. M. Borsa, S. Grachev, C. Presura and D. O. Boerma, "Growth and Properties of $\mathrm{Cu}_{3} \mathrm{~N}$ Films and $\mathrm{Cu} 3 \mathrm{~N} / \gamma^{\prime}$ $\mathrm{Fe}_{4} \mathrm{~N}$ Bilayers," Applied Physics Letters, Vol. 80, No. 10, 2002, pp. 1823-1825. doi:10.1063/1.1459116

[15] U. Hahn and W. Weber, "Electronic Structure and Chemical-Bonding Mechanism of $\mathrm{Cu}_{3} \mathrm{~N}$, $\mathrm{Cui}_{3} \mathrm{NPd}$, and Re- 
lated Cu(I) Compounds," Physical Review B, Vol. 53, No. 19, 1996, pp. 12684-12693. doi:10.1103/PhysRevB.53.12684

[16] M. G. Moreno-Armenta, W. L. Perez and N. Takeuchi, "First-Principles Calculations of the Structural and Electronic Properties of $\mathrm{Cu}_{3} \mathrm{MN}$ Compounds with $\mathrm{M}=\mathrm{Ni}, \mathrm{Cu}$, Zn, Pd, Ag, and Cd," Solid State Sciences, Vol. 9, No. 2, 2007, pp. 166-172. doi:10.1016/j.solidstatesciences.2006.12.002

[17] J. Wang, J. T. Chen, X. M. Yuan, Z. G. Wu, B. B. Miao and P. X. Yan, "Copper Nitride $\left(\mathrm{Cu}_{3} \mathrm{~N}\right)$ Thin Films Deposited by RF Magnetron Sputtering," Journal of Crystal Growth, Vol. 286, No. 2, 2006, pp. 407-412. doi:10.1016/j.jcrysgro.2005.10.107

[18] K. V. S. Reddy, S. S. Reddy, P. S. Reddy and S. Uthana, "Copper Nitride Films Deposited by Dc Reactive Magnetron Sputtering," Journal of Materials Science: Materials in Electronics, Vol. 18, No. 10, 2007, pp. 1003-1008. doi:10.1007/s10854-007-9120-0

[19] G. H. Yue, P. X. Yan, J. Z. Liu, M. X. Wang, M. Li and X. M. Yuan, "Copper Nitride Thin Film Prepared by Reactive Radio-Frequency Magnetron Sputtering," Journal of Applied Physics, Vol. 98, No. 10, 2005, Article ID: 103506. doi:10.1063/1.2132507

[20] N. Gordillo, R. Gonzalez-Arrabal, A. Alvarez-Herrero and F. Agullo-Lopez, "Free-Carrier Contribution to the Optical Response of N-Rich $\mathrm{Cu}_{3} \mathrm{~N}$ Thin Films," Journal of Physics D: Applied Physics, Vol. 42, No. 16, 2009, Article ID: 165101. doi:10.1088/0022-3727/42/16/165101

[21] T. Maruyama and T. Morishita, "Copper Nitride Thin Films Prepared by Radio-Frequency Reactive Sputtering," Journal of Applied Physics, Vol. 78, No. 6, 1995, pp. 4104-4107. doi:10.1063/1.359868

[22] K. J. Kim, J. H. Kim and J. H. Kang, "Structural and Optical Characterization of $\mathrm{Cu}_{3} \mathrm{~N}$ Films Prepared by Reactive RF Magnetron Sputtering," Journal of Crystal Growth, Vol. 222, No. 4, 2000, pp. 767-772. doi:10.1016/S0022-0248(00)00968-4

[23] Y. Du, A. L. Ji, L. B. Ma, Y. Q. Wang and Z. X. Cao, "Electrical Conductivity and Photoreflectance of Nanocrystalline Copper Nitride Thin Films Deposited at Low Temperature," Journal of Crystal Growth, Vol. 280, No. 3-4, 2005, pp. 490-494. doi:10.1016/j.jcrysgro.2005.03.077

[24] J. F. Pierson and D. Horwat, "Addition of Silver in Copper Nitride Films Deposited by Reactive Magnetron Sputtering," Scripta Materiala, Vol. 58, No. 7, 2008, pp. 568570. doi:10.1016/j.scriptamat.2007.11.016

[25] A. Rahmati, H. Bidadi, K. Ahmadi and F. Hadian, "Ti Substituted Nano-Crystalline $\mathrm{Cu}_{3} \mathrm{~N}$ Thin Films," Journal of Coatings Technology and Research, Vol. 8, No. 2, 2011, pp. 289-297. doi:10.1007/s11998-010-9279-9

[26] A. Rahmati, "Reactive DC Magnetron Sputter Deposited Ti-Cu-N Nano-Composite Thin Films at Nitrogen Ambient," Vaccum, Vol. 85, No. 9, 2011, pp. 853-860. doi:10.1016/j.vacuum.2010.12.010

[27] J. F. Pierson, D. Wiederkehr and A. Billard, "Reactive Magnetron Sputtering of Copper, Silver, and Gold," Thin
Solid Films, Vol. 478, No. 1-2, 2005, pp. 196-205. doi:10.1016/j.tsf.2004.10.043

[28] I. S. Kim and P. N. Kumta, "Hydrazide Sol-Gel Process: A Novel Approach, for Synthesizing Nanostructured Titanium Nitride," Materials Science and Engineering: B, Vol. 98, No. 2, 2003, pp. 123-134. doi:10.1016/S0921-5107(02)00595-0

[29] B. Subramanian, K. Ashok and M. Jayachandran, "Effect of Substrate Temperature on the Structural Properties of Magnetron Sputtered Titanium Nitride Thin Films with Brush Plated Nickel Interlayer on Mild Steel," Applied Surface Science, Vol. 255, No. 5, 2008, pp. 2133-2138. doi:10.1016/j.apsusc.2008.07.083

[30] Z. Wang, S. A. Cohen, D. N. Ruzic and M. Goeckner, "Nitrogen Atom Energy Distribution in a Hollow-Cathode Planar Sputtering Magnetron," Journal of Physical Review E, Vol. 61, No. 2, 2000, pp. 1904-1911.

[31] A. Rahmati, H. Bidadi, K. Ahmadi and F. Hadian, "Reactive DC Magnetron Sputter Deposited Titanium-CopperNitrogen Nano-Composite Thin Films with an Argon/ Nitrogen Gas Mixture," Plasma Science and Technology, Vol. 12, No. 6, 2010, pp. 1-7. doi:10.1088/1009-0630/12/6/09

[32] J. F. Pierson, "Structure and Properties of Copper Nitride Films Formed by Reactive Magnetron Sputtering," Vacuum, Vol. 66, No. 1, 2002, pp. 59-64. doi:10.1016/S0042-207X(01)00425-0

[33] X. Y. Fan, Z. G. Wu and G. A. Zhang, "Ti Dopped Copper Nitride Films Deposited by Cylindrical Magnetron Sputtering," Journal of Alloys and Compounds, Vol. 440, 2007, p. 54.

[34] J. L. Vossen and W. Kern, "Thin Film Process II," Academic Press, New York, 1991, pp. 181-186.

[35] J. A. Thornton, "The Microstructure of Sputter-Deposited Coatings," Journal of Vacuum Science \& Technology A, Vol. 4, No. 6, 1986, pp. 3059-3065. doi: $10.1116 / 1.573628$

[36] S. Mahieu and D. Depla, "Reactive Sputter Deposition of TiN Layers: Modelling the Growth by Characterization of Particle Fluxes towards the Substrate," Journal of Physics D: Applied Physics, Vol. 42, No. 5, 2009, Article ID: 053 002. doi:10.1088/0022-3727/42/5/053002

[37] R. Behrisch and W. Eckstein, "Sputtering by Particle Bombardment, Experiments and Computer Calculations from Threshold to MeV Energies," Spriger, New York, 2007.

[38] Y. Yamamura, T. Takiguchi and M. Ishida, "Energy and Angular Distributions of Sputtered Atoms at Normal Incadence," Radiation Effects and Defects in Solids, Vol. 118, No. 3, 1991, pp. 237-261. doi:10.1080/10420159108221362

[39] L. R. Shaginyan, Y. I. Kim, J. G. Han, N. V. Britun, J. Musil and I. V. Belousov, "Novel Model for Film Growth Based on Surface Temperature Developing during Magnetron Sputtering," Surface and Coatings Technology, Vol. 202, No. 3, 2007, pp. 486-493. doi:10.1016/j.surfcoat.2007.06.016

[40] M. Delfino, J. A. Fair and D. Hodul, "X-Ray Photoemis- 
sion Spectra of Reactively Sputtered TiN," Journal of Applied Physics, Vol. 71, 1992, pp. 6079-6085.

doi:10.1063/1.350465

[41] E. G. Birgin, I. Chambouleyron and J. M. Martınez, "Estimation of the Optical Constants and the Thickness of Thin Films Using Unconstrained Optimization," Journal of Computational Physics, Vol. 151, No. 2, 1999, pp.
862-990. doi:10.1006/jcph.1999.6224

[42] D. Poelman and P. F. Smet, "Methods for the Determination of the Optical Constants of Thin Films from Single Transmission Measurements: A Critical Review," Journal of Physics D: Applied Physics, Vol. 36, No. 15, 2003, p. 1850. doi:10.1088/0022-3727/36/15/316 